\title{
Détermination de certains acides aminés limitants chez la vache laitière par la méthode des administrations post-ruminales
}

H. RULQUIN
Station de Recherches sur la Vache Laitière, I.N.R.A., Saint-Gilles, 35500 L'Hermitage, France.

Summary. The effects of postruminal infusion of methionine (MET), lysine (LYS), threonine (THR) and histidine (HIS) were tested against control infusion of glutamic acid using dairy cows in two latin squares. In the first trial milk $(\mathrm{kg} / \mathrm{d})$ and protein $(\mathrm{g} / \mathrm{d})$ productions for the control, MET, LYS, MET + LYS were $26.3,754 ; 26.9,774 ; 27.0,775 ; 27.6,790$, respectively. In the second trial they were $24.8,721 ; 25.1,759 ; 25.4,761 ; 24.9,763$ for the control, MET + LYS, MET + LYS + THR and MET + LYS + THR + HIS, respectively. With the diet in which $26 \%$ of the proteins were corn proteins, MET and LYS were co-limiting amino acids, whereas THR and HIS were not.

L'accroissement de la sécrétion des protéines du lait consécutif à un apport post-ruminal de protéines dépend de la composition en acides aminés de celles-ci (Rogers et al., 1984), notamment en acides aminés indispensables (Rulquin, 1986). La lysine, la méthionine, la thréonine, l'histidine et la phénylalanine pourraient être les acides aminés les plus limitants (Clark, 1975). Nous avons cherché à le vérifier, en réalisant des infusions duodénales des 4 premiers acides aminés chez la vache laitière.

Matériel et méthodes. Cinq vaches Pie-noires ont servi dans 2 essais consécutifs (débutant respectivement en $10^{\circ}$ et $18^{\circ}$ semaine de lactation) organisés selon des carrés latins $4 \times 4$ comportant des périodes de $15 \mathrm{j}$. Au cours de ces essais elles ont reçu directement dans le duodénum 11,7 g d'azote/j apporté en continu au moyen de solutions d'acides aminés dont la composition est donnée au tableau 1. La ration était constituée (en MS) de $31 \%$ de maïs (plante entière) déshydraté, $24 \%$ de pulpes de betteraves déshydratées, $27 \%$ d'aliment concentré, $14 \%$ de foin de prairie naturelle, $2 \%$ d'urée, $2 \%$ de complément minéral. Elle contenait $14,2 \%$ de matières azotées dont $26 \%$ provenant du maïs. Elle était distribuée de façon à couvrir les besoins énergétiques et $80 \%$ des besoins azotés. La production de lait a été enregistrée tous les jours, sa composition étant déterminée chaque semaine à partir d'échantillons provenant de 6 traites consécutives.

Résultats et discussion. La lysine et la méthionine, infusées isolément, $n^{\prime}$ ont pas d'effet $(P<0,05)$ sur les productions, alors que, infusées conjointement, elles augmentent significativement dans les 2 essais la production de protéines de $5 \%$ (tabl. 1). En fonction du stade de lactation, cette augmentation est due tout d'abord à celle de la quantité de lait, puis ensuite à celle du taux protéique du lait. Cette réponse représente $46 \%$ de celle obtenue pour le même régime avec une infusion de caséine (Rulquin, 1986). L'adjonction de thréonine et d'histidine à ce mélange n'apporte pas d'augmentations supplémentaires (tabl. 1). Les résultats concernant la lysine, la méthionine et l'histidine sont comparables à ceux de Schwab, Satter et Clay (1976). Ces auteurs avaient, par contre, obtenu une augmentation de la production des protéines du lait en ajoutant de la thréonine au mélange méthionine + lysine avec des rations dont $43 \%$ des protéines provenaient du maïs.

Pour les vaches laitières alimentées avec des rations à base de maïs, la lysine et la méthionine sont des acides aminés limitants alors que I'histidine et la thréonine ne le sont pas.

Remerciements. - Nous remercions I'A.E.C. pour sa coopération à cette étude.

Clark J. H., 1975. J. Dairy Sci., 58, 1178-1197.

Rogers J. A., Clark J. H., Drendel T. R., Fahey G. C., 1984. J. Dairy Sci, 67, 1928-1935.

Rulquin H., 1986. Reprod. Nutr. Dévelop., 26, 347-348.

Schwab C. G., Satter L. D., Clay A. B., 1976. J. Dairy Sci., 59, 1254-1270. 


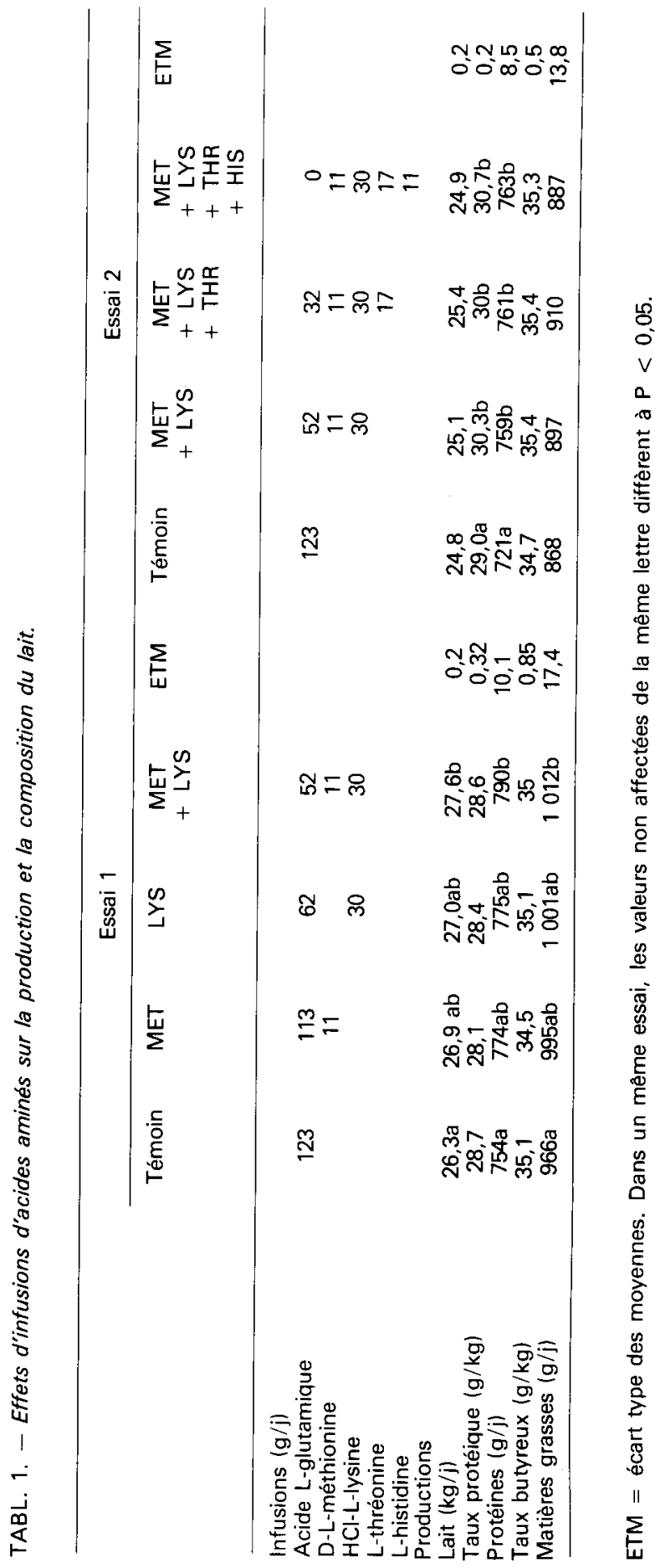

